Journal of Engineering and Applied Sciences 14 (21): 8034-8038, 2019

ISSN: 1816-949X

(C) Medwell Journals, 2019

\title{
Optimal Power Flow Based on Bird Swarm Optimization and Genetic Algorithm
}

\author{
Ahmed Muhsin Abdul Majeed \\ Department of Electrical Engineering, University of Baghdad, Jaderia, Baghdad, Iraq \\ amhamzah66@gmail.com,+96407800529554
}

\begin{abstract}
The most important demands for a power system is operating with a minimum cost with suitable system constraints. The system constraints which kept within a satisfactory limits such as voltage magnitudes of all load buses, real power, reactive power at each bus. This study proposed two optimization techniques: bird swarm optimization and Genetic algorithm. These optimization techniques are implemented on IEEE 30 bus test system. The model of proposed system is developed in the MATLAB and its simulated results have demonstrated the satisfactory values.
\end{abstract}

Key words: Optimal power flow, optimization techniques, bird optimization, MATLAB, bus test system, voltage magnitudes

\section{INTRODUCTION}

An Optimal Power Flow (OPF) plays an important role in electrical power system due to the keys of system operation and planning must be economic and secure. Recently, there are many considerations have been supplemented by researches and industrial countries (Weedy et al., 2012). The capability to gain a satisfactory amount of power flow with a minimum losses, particularly an optimal power flow based on optimization techniques has been developed (Zhang and Li, 2010). Different optimization techniques have been involved to solve the power flow problems such as Optimal Power Flow (OPF). Even though the optimization problem is a mathematical model the main objective is to minimize undesirable things such fuel costs, errors and energy system losses in contrast the maximum desirable things such as efficiency and system stability (Hoolimath et al., 2012; Bansal, 2005; Mohamed et al., 2009).

To provide better economic dispatch as well as to reduce the total generation cost, an optimal power flow model with the transmission line impedance considered as a flexible model that it is formulated as a mixed integer quadratic programming is presented (Ding et al., 2015). The generation cost will be minimized according of increasing the range of impedance and consequently it will be appeared difficulty with large networks.

To solve the OPF problems, a local solutions of OPF is presented (Bukhsh et al., 2013). This method is interested to find a voltage profile within its limits for a stressed network and this local solution is close to global values. In contrast, a global optimal solutions have been discussed by Wang et al. (2007). However, the proposed techniques in this study can be implemented in real time applications to solve commutation issues of large scale market based $\mathrm{OPF}$. In order to emphasis and concentrate of optimal generation cost by integrating new formulations and optimizing algorithms. Combing the non convex optimization algorithms to achieve an adequate voltage profile for $\mathrm{OPF}$ constraints.

In this study, a Bird Swarm Optimization (BSO) and Genetic Algorithm (GA) have been introduced to investigate in order to deal with an optimal power flow. In spite of GA requires tremendously high time but it has an advantages such as a set of solutions from one generation to the next and not a single solution, thus, making it less likely to converge on local minima. In addition, GA based on mutation and crossover that the solutions are developed randomly (Ding et al., 2015; Bukhsh et al., 2013; Wang et al., 2007; Bhavani and Kumar, 2014). As well as GA necessity is only involves rough information of the objective function. BSO has been considered due to simplification of the social behaviors and social interactions in bird swarms. It mimics the bird's foraging behavior, vigilance behavior and flight behavior. Thus, the swarm intelligence can be efficiently extracted from the bird swarms to optimize problems (Bansal, 2005).

Since, the constraints in the electric power system is inherently nonlinear then the proposed objective function is nonlinear under contingency conditions (Ding et al., 2015). It is also, the research (Bukhsh et al., 2013) has developed a modified bacterial foraging algorithm incorporated with FACTS to solve the optimal power flow. However these FACTS devices force the power system to operate in a complex manner. 


\section{MATERIALS AND METHODS}

Optimal power flow problem: The undesirable factor fuel cost is adjusted to a minimum to be an objective function for optimal power flow problem. This minimal fuel cost is stated as:

$$
\text { Minimize } F=\sum^{\mathrm{Ng}}\left(\mathrm{A}_{\mathrm{i}} \mathrm{P}_{\mathrm{gi}}^{2}+\mathrm{B}_{\mathrm{i}} \mathrm{P}_{\mathrm{gi}}+\mathrm{C}\right) \$ / \mathrm{h}
$$

where, $\mathrm{A}-\mathrm{C}$ are the cost parameters as given in Appendix. Equation 1 is balanced due to active power $\mathrm{P}_{\mathrm{i}}(\mathrm{V}, \boldsymbol{\delta})-\mathrm{P}_{\mathrm{gi}}+\mathrm{P}_{\mathrm{di}}$ $=0 \mathrm{i}=1,2, \ldots, \mathrm{N}_{\mathrm{b}}$ and reactive power $\mathrm{Q}_{\mathrm{i}}(\mathrm{V}, \boldsymbol{\delta})-\mathrm{Q}_{\mathrm{gi}}+\mathrm{Q}_{\mathrm{di}}=0$ $i=N_{v+1}, N_{v+2}, \ldots, N_{b}$ limits on real power, voltage magitude and voltage angles, respectively, $\mathrm{P}_{\mathrm{gi}}^{\text {nin }} \leq \mathrm{P}_{\mathrm{gi}} \leq \mathrm{P}_{\mathrm{gi}}^{\text {max }}$ :

$$
\begin{gathered}
V_{i}^{\text {min }} \leq V_{i} \leq V_{i}^{\max } \\
\delta_{i}^{\min } \leq \delta_{i} \leq \delta_{1}^{\max } \quad i=1,2, \ldots, N_{b}
\end{gathered}
$$

Where:

$\mathrm{P}_{\mathrm{g} i}=$ The active power from bus $\mathrm{g}$ to bus $\mathrm{i}$

$\mathrm{V}_{\mathrm{i}}=$ The voltage magnitude at bus $\mathrm{i}$

The real power flow Eq. 2 is:

$$
\begin{gathered}
P_{i}(V, \delta)=\sum_{i=1}^{N_{b}} V_{i} V_{j}\left(G_{i j} \cos \delta_{i j}+B_{i j} \sin \delta_{i j}\right) \\
Q_{i}(V, \delta)=\sum_{i=1}^{N_{b}} V_{i} V_{j}\left(G_{i j} \sin \left(\delta_{i j}\right)-\mid B_{i j} \cos \left(\delta_{i j}\right)\right)
\end{gathered}
$$

Case study; IEEE 30 bus test system: The proposed method was tested in the IEEE 30-bus, 6 generator test system that has a total load $283.400 \mathrm{MW}, 126.200 \mathrm{MVAR}$ MVAR and MVA base is 100 MVA. The active and reactive power losses of the system are 18.403 MW and 29.125 MVAR, respectively. The single line diagram of a 30 bus test system is shown in Fig 1. Appendix gives the details of IEEE 30 bus test system data.

Bird swarm optimization for OPF: The basic steps for a bird swarm optimization is summarized in the flowchart as shown in Fig. 2. Each bird searches for food according to, its experience and the swarms as follows:

$$
\mathrm{x}_{\mathrm{i}, \mathrm{j}}^{\mathrm{t}+1}=\mathrm{x}_{\mathrm{i}, \mathrm{j}}^{\mathrm{t}}+\left(\mathrm{p}_{\mathrm{i}, \mathrm{j}}-\mathrm{x}_{\mathrm{i}, \mathrm{j}}^{\mathrm{t}}\right) \times \mathrm{C} \times \text { rand }(0,1)+\left(\mathrm{g}_{\mathrm{i}}-\mathrm{x}_{\mathrm{i}, \mathrm{j}}^{\mathrm{t}}\right) \times \mathrm{S} \times \operatorname{rand}(0,1)
$$

where, $p_{i, j}$ is the best previous position of the ith bird and $\mathrm{g}_{\mathrm{j}}$ the best previous position shared by the swarm. The flight behavior can be described mathematically as follows:

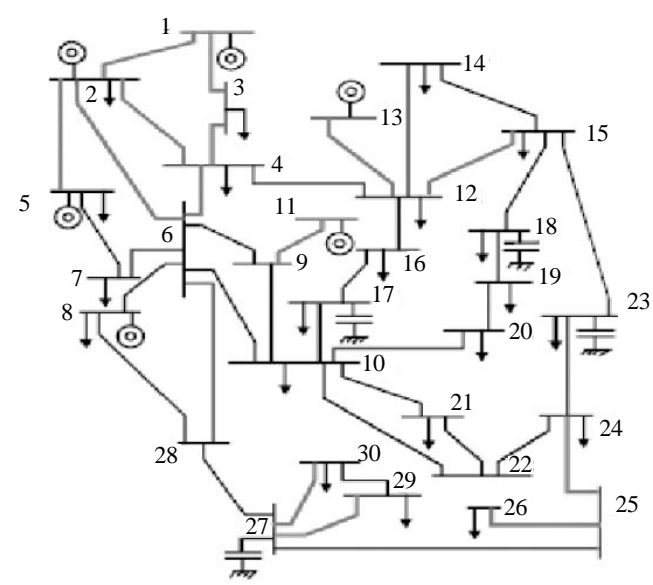

Fig. 1: IEEE 30 bus test system single line diagram

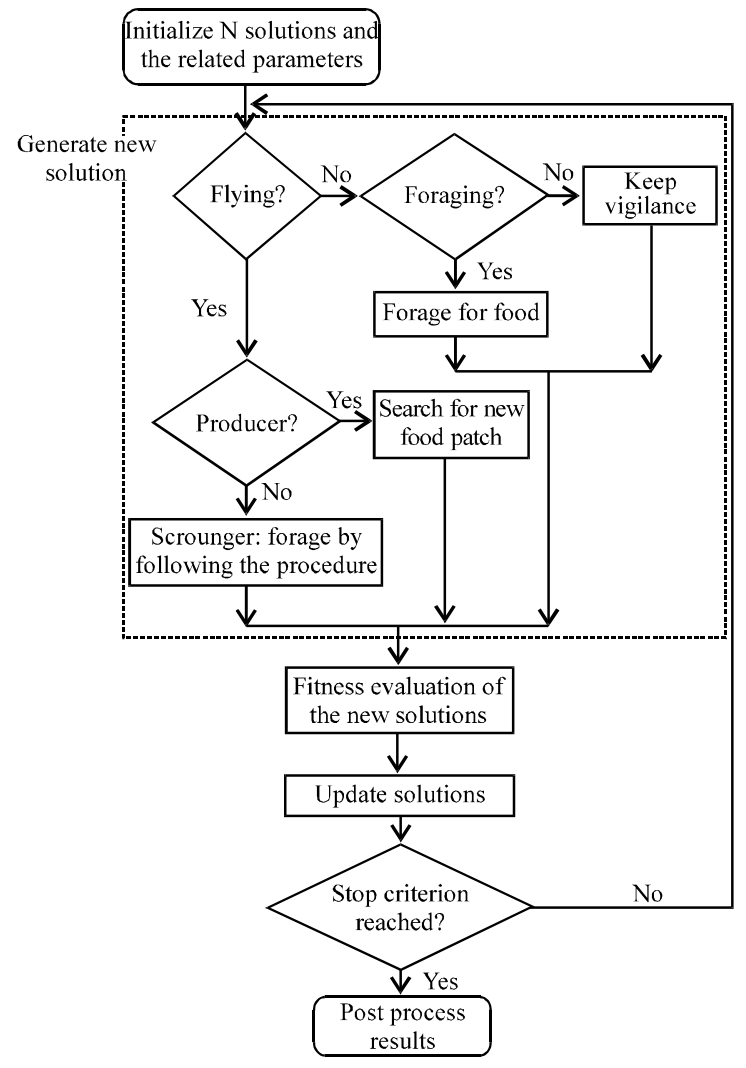

Fig. 2: Bird swarm optimization flowchart

$$
\begin{aligned}
& x_{i, j}^{t+1}=x_{i, j}^{t}+\operatorname{randn}(0,1) \times x_{i, j}^{t}, \\
& x_{i, j}^{t+1}=x_{i, j}^{t}+\left(x_{k . j}^{t}-x_{i, j}^{t}\right) \times F L \times \operatorname{rand}(0,1)
\end{aligned}
$$

where, randn $(0,1)$ denotes Gaussian distributed random number, C, S, a1, a2, FL: five constant parameters, taking $\mathrm{C}=\mathrm{S}=1.5$, al $=\mathrm{a} 2=1, \mathrm{P} \epsilon(0.8,1), \mathrm{Fl} \epsilon(0.5,0.9)$ and 
$\mathrm{FQ}=3$, initialize the population and define the related parameters. Evaluate the $\mathrm{N}$ individual's fitness value and find the best solution. If the new solutions are better than their previous ones, update them to find the current best solution. The individual with the best objective function value in the population. The parameters in $\mathrm{BSO}$ are presented as follows:

- Set the default parameters: lower and upper bounds

- Formation of Y bus

- Formation of the diagonal elements

- Initializing Jacobian matrix

- Initialization the individual's best fitness value

- Divide the bird swarm into two parts: producers and scroungers

- Update the individual's best fitness value and the global best one

- Objective function $\mathrm{y}=\operatorname{Sphere}(\mathrm{x})$

- The obtained simulation results are fuel cost $=$ $822.9344 \$ / h$

This fuel cost can be improved by changing bird flight behavior dynamically.

\section{RESULTS AND DISCUSSION}

Genetic algorithm for OPF: The flowchart in Fig. 3 summarized the execution processes of the GA that includes the steps of initialization, selection, crossover and mutation then finally, the new generation. The generation and the fitness values as follows. $F=$ $801.9463 \$ / \mathrm{h}$ with the active generating power for each generators as Pgg $=(178.2460,50.3148,21.9006,21.1074$, $11.4689,9.8821)$ MW as shown in Fig. 4 a when the generations are 200. The total losses is 9.5197 MW.

When the optimization is repeated when the generations is 50 then the following results will be obtained, $F=823.2186 \$$ h, Pgg $=(192.1325,24.7690$, $16.4970,15.9747,30.0000,13.8644) \mathrm{MW}$ as shown in Fig. 4b. The total losses is $9.8375 \mathrm{MW}$. It can be observed from Table 1 and 2 that the obtained different expected objective function values due to uncertainty level of the inputs corresponding to get minimum fuel cost for various No. of generations. Knowing that base $=100 \mathrm{MVA}$ and the accuracy is 0.0001 . It can be seen that as taking the fuel cost as an objective function then after OPF with a minimum objection function has to be considered.

However, these obtained values are a little bit higher than the results when a bacterial foraging algorithm is used, since, the active power loss is $8.4625 \mathrm{MW}$ and the fuel cost is $800.1585 \$ / h$ due to significant of incorporating the FACTS in the system (Bukhsh et al., 2013) (Tablel and 2):

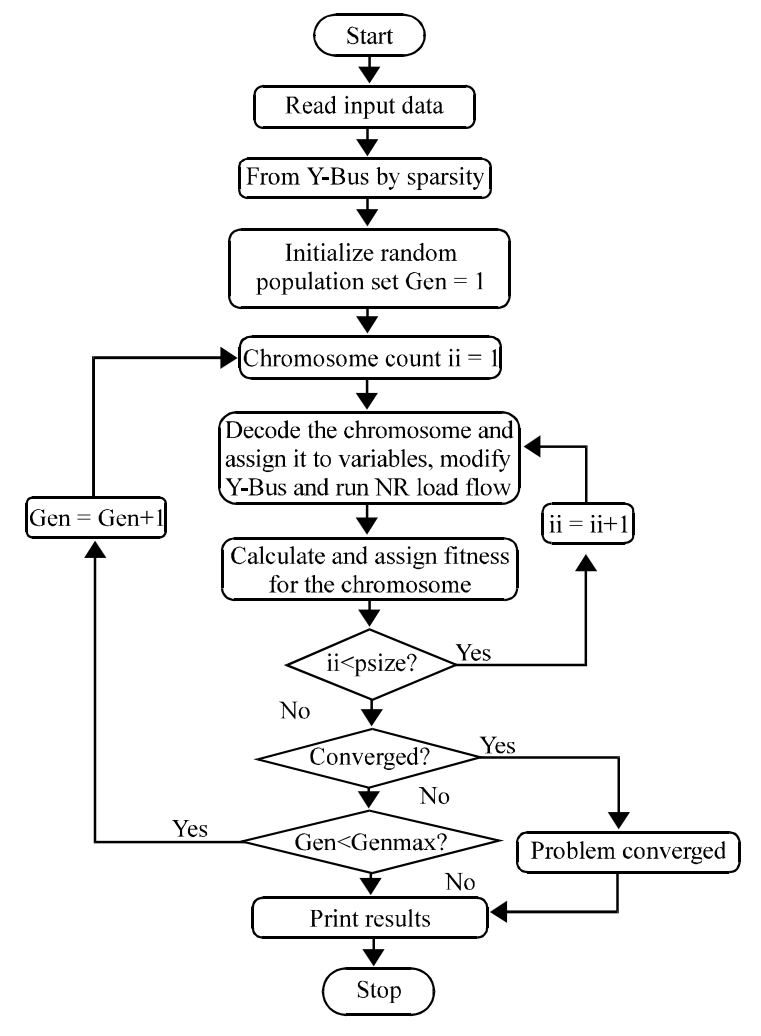

Fig. 3: GA flowchart
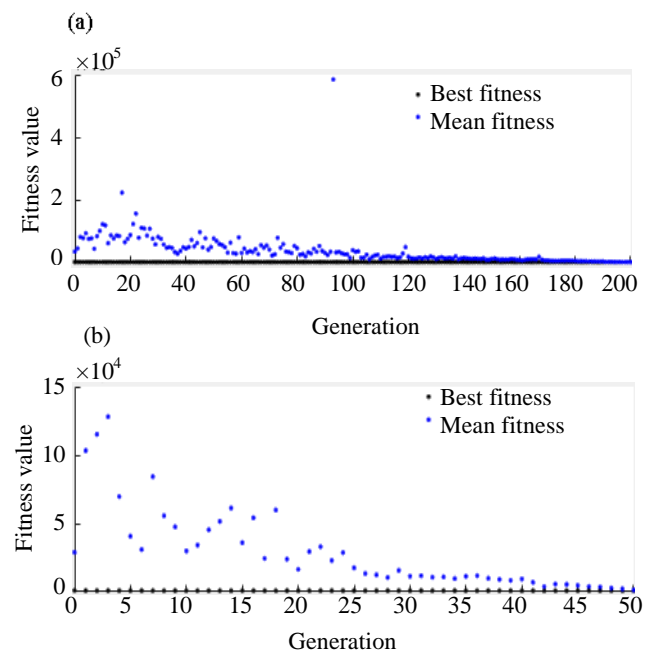

Fig. 4: Fittnes values with respect to generation: a) When generations is 200; Best: 801.946; Mean: 882.292 and b) When generations is 50; Best: 823.219; Mean: 1394.87

- The steps for simulation:

- Read input data: bus data line data generator cost

- Test for max. power mismatch

- Initializing Jacobian matrix 


\begin{tabular}{lc}
\multicolumn{2}{l}{ Table 1: The active power generation for each generator } \\
\hline Gen. No. & Active power generation (MW) \\
\hline G1 & 178.2460 \\
G2 & 50.3148 \\
G3 & 21.9006 \\
G4 & 21.1074 \\
G5 & 11.4689 \\
G6 & 9.8821 \\
Total losses & 9.5197 \\
Total cost & $801.9463 \$ / \mathrm{h}$ \\
\hline & \\
Table 2: The active power generation for each generator \\
\hline Gen. No. \\
\hline G1 & 192.1325 \\
G2 & 24.7690 \\
G3 & 16.4970 \\
G4 & 15.9747 \\
G5 & 30.0000 \\
G6 & 13.8644 \\
Total losses & 9.8375 \\
Total cost & $823.2186 \$ \mathrm{~h}$ \\
\hline
\end{tabular}

- The Mvar of generator buses are tested. If not within limits $\operatorname{Vm}(\mathrm{n})$ is changed in steps of 0.01 pu to bring the generator Mvar within the specified limits

- Power flow solution by Newton-Raphson method

- Set GA parameters: population size $=50$

- Crossover: explores new generations

- Mutation: avoids premature convergence of the population (Table1 and 2)

\section{CONCLUSION}

Despite advances in mathematical optimization techniques have yet to accomplish firm and dependable applications in power system planning and operation. The objective is formulated as an optimization problem to minimize the total system losses in the system as well as total fuel cost. A knowledge based system can improve the facilities of a power system where GA can obtain knowledge through well-established models. It is simple in implementation but has slow convergence for $\mathrm{OPF}$. A satisfactory simulation results for OPF using bird swarm optimization can be improved with a dynamic change of frequency of bird flight behavior.

\section{NOMENCLATURE}

$\begin{array}{ll}\text { Parameters } & \\ \mathrm{A}, \mathrm{B} \text { and } \mathrm{C} & \text { Cost parameters } \\ \mathrm{P}_{\mathrm{i}}(\mathrm{V}, \delta) & \text { Active power } \\ \mathrm{Q}_{\mathrm{i}}(\mathrm{V}, \delta) & \text { Reactive power } \\ \mathrm{F} & \text { Minimal fuel cost } \\ \mathrm{V}_{\mathrm{i}}^{\text {min }} \leq \mathrm{V}_{\mathrm{i}} \leq \mathrm{V}_{\mathrm{i}}^{\text {max }} & \text { Voltage magitude limits } \\ \delta_{\mathrm{i}}^{\text {min }} \leq \delta_{\mathrm{i}} \leq \delta_{\mathrm{i}}^{\text {max }} & \text { Voltage angles limits } \\ \text { randn }(0,1) & \text { Gaussian distributed random number } \\ \mathrm{C}, \mathrm{S}, \mathrm{a} 1, \mathrm{a} 2, \mathrm{FL} & \text { Five constant parameters }\end{array}$

\section{APPENDIX}

IEEE 30-bus test system

busdata

Bus bus voltage angle load generator injected

\begin{tabular}{llllllllllll}
\multicolumn{1}{l}{ No code Mag. Deg MW Mvar MW Mvar Qmin Qmax Mvar } \\
1 & 1 & 1.06 & 0.0 & 0.0 & 0.0 & 0.0 & 0.0 & 0 & 0 & 0 \\
2 & 2 & 1.043 & 0.0 & 21.70 & 12.7 & 40.0 & $0.0-40$ & 50 & 0 & \\
3 & 0 & 1.0 & 0.0 & 2.4 & 1.2 & 0.0 & 0.0 & 0 & 0 & 0 \\
4 & 0 & 1.06 & 0.0 & 7.6 & 1.6 & 0.0 & 0.0 & 0 & 0 & 0 \\
5 & 2 & 1.01 & 0.0 & 94.2 & 19.0 & 0.0 & $0.0-40$ & 40 & 0 & \\
6 & 0 & 1.0 & 0.0 & 0.0 & 0.0 & 0.0 & 0.0 & 0 & 0 & 0 \\
7 & 0 & 1.0 & 0.0 & 22.8 & 10.9 & 0.0 & 0.0 & 0 & 0 & 0 \\
8 & 2 & 1.01 & 0.0 & 30.0 & 30.0 & 0.0 & $0.0-10$ & 60 & 0 & \\
9 & 0 & 1.0 & 0.0 & 0.0 & 0.0 & 0.0 & 0.0 & 0 & 0 & 0 \\
10 & 0 & 1.0 & 0.0 & 5.8 & 2.0 & 0.0 & $0.0-6$ & 24 & 19 & \\
11 & 2 & 1.082 & 0.0 & 0.0 & 0.0 & 0.0 & 0.0 & 0 & 0 & 0 \\
12 & 0 & 1.0 & 0 & 11.2 & 7.5 & 0 & 0 & 0 & 0 & 0 \\
13 & 2 & 1.071 & 0 & 0 & 0.0 & 0 & $0-6$ & 24 & 0 & \\
14 & 0 & 1 & 0 & 6.2 & 1.6 & 0 & 0 & 0 & 0 & 0 \\
15 & 0 & 1 & 0 & 8.2 & 2.5 & 0 & 0 & 0 & 0 & 0 \\
16 & 0 & 1 & 0 & 3.5 & 1.8 & 0 & 0 & 0 & 0 & 0 \\
17 & 0 & 1 & 0 & 9.0 & 5.8 & 0 & 0 & 0 & 0 & 0 \\
18 & 0 & 1 & 0 & 3.2 & 0.9 & 0 & 0 & 0 & 0 & 0 \\
19 & 0 & 1 & 0 & 9.5 & 3.4 & 0 & 0 & 0 & 0 & 0 \\
20 & 0 & 1 & 0 & 2.2 & 0.7 & 0 & 0 & 0 & 0 & 0 \\
21 & 0 & 1 & 0 & 17.5 & 11.2 & 0 & 0 & 0 & 0 & 0 \\
22 & 0 & 1 & 0 & 0 & 0.0 & 0 & 0 & 0 & 0 & 0 \\
23 & 0 & 1 & 0 & 3.2 & 1.6 & 0 & 0 & 0 & 0 & 0 \\
24 & 0 & 1 & 0 & 8.7 & 6.7 & 0 & 0 & 0 & 0 & 4.3 \\
25 & 0 & 1 & 0 & 0 & 0.0 & 0 & 0 & 0 & 0 & 0 \\
26 & 0 & 1 & 0 & 3.5 & 2.3 & 0 & 0 & 0 & 0 & 0 \\
27 & 0 & 1 & 0 & 0 & 0.0 & 0 & 0 & 0 & 0 & 0 \\
28 & 0 & 1 & 0 & 0 & 0.0 & 0 & 0 & 0 & 0 & 0 \\
29 & 0 & 1 & 0 & 2.4 & 0.9 & 0 & 0 & 0 & 0 & 0 \\
30 & 0 & 1 & 0 & 10.6 & 1.9 & 0 & 0 & 0 & 0 & 0
\end{tabular}

Line data:

\begin{tabular}{|c|c|c|c|c|c|}
\hline \\
\hline 1 & 2 & 0.0192 & \multicolumn{3}{|c|}{ Bus bus $\mathrm{R} \times 1 / 2 \mathrm{~B}$ Line } \\
\hline 1 & 3 & 0.0452 & 0.1852 & 0.02040 & 1 \\
\hline 2 & 4 & 0.0570 & 0.1737 & 0.01840 & 1 \\
\hline 3 & 4 & 0.0132 & 0.0379 & 0.00420 & 1 \\
\hline 2 & 5 & 0.0472 & 0.1983 & 0.02090 & 1 \\
\hline 2 & 6 & 0.0581 & 0.1763 & 0.01870 & 1 \\
\hline 4 & 6 & 0.0119 & 0.0414 & 0.00450 & 1 \\
\hline 5 & 7 & 0.0460 & 0.1160 & 0.01020 & 1 \\
\hline 6 & 7 & 0.0267 & 0.0820 & 0.00850 & 1 \\
\hline 6 & 8 & 0.0120 & 0.0420 & 0.00450 & 1 \\
\hline 6 & 9 & 0.0 & 0.2080 & 0.0 & 0.978 \\
\hline 6 & 10 & 0 & 0.5560 & 0 & 0.969 \\
\hline 9 & 11 & 0 & 0.2080 & 0 & 1 \\
\hline 9 & 10 & 0 & 0.1100 & 0 & 1 \\
\hline 4 & 12 & 0 & 0.2560 & 0 & 0.932 \\
\hline 12 & 13 & 0 & 0.1400 & 0 & 1 \\
\hline 12 & 14 & 0.1231 & 0.2559 & 0 & 1 \\
\hline 12 & 15 & 0.0662 & 0.1304 & 0 & 1 \\
\hline 12 & 16 & 0.0945 & 0.1987 & 0 & 1 \\
\hline 14 & 15 & 0.2210 & 0.1997 & 0 & 1 \\
\hline 16 & 17 & 0.0824 & 0.1923 & 0 & 1 \\
\hline 15 & 18 & 0.1073 & 0.2185 & 0 & 1 \\
\hline 18 & 19 & 0.0639 & 0.1292 & 0 & 1 \\
\hline 19 & 20 & 0.0340 & 0.0680 & 0 & 1 \\
\hline 10 & 20 & 0.0936 & 0.2090 & 0 & 1 \\
\hline 10 & 17 & 0.0324 & 0.0845 & 0 & 1 \\
\hline 10 & 21 & 0.0348 & 0.0749 & 0 & 1 \\
\hline 10 & 22 & 0.0727 & 0.1499 & 0 & 1 \\
\hline 21 & 22 & 0.0116 & 0.0236 & 0 & 1 \\
\hline 15 & 23 & 0.1000 & 0.2020 & 0 & 1 \\
\hline 22 & 24 & 0.1150 & 0.1790 & 0 & 1 \\
\hline 23 & 24 & 0.1320 & 0.2700 & 0 & 1 \\
\hline 24 & 25 & 0.1885 & 0.3292 & 0 & 1 \\
\hline 25 & 26 & 0.2544 & 0.3800 & 0 & 1 \\
\hline 25 & 27 & 0.1093 & 0.2087 & 0 & 1 \\
\hline 28 & 27 & 0 & 0.3960 & 0 & 0.968 \\
\hline 27 & 29 & 0.2198 & 0.4153 & 0 & 1 \\
\hline 27 & 30 & 0.3202 & 0.6027 & 0 & 1 \\
\hline 29 & 30 & 0.2399 & 0.4533 & 0 & 1 \\
\hline 8 & 28 & 0.0636 & 0.2000 & 0.0214 & 1 \\
\hline 6 & 28 & 0.0169 & 0.0599 & 0.065 & 1 \\
\hline
\end{tabular}




\begin{tabular}{|c|c|c|c|c|c|c|c|c|c|c|c|c|}
\hline \multirow[b]{2}{*}{ Units } & \multirow[b]{2}{*}{ Bus } & \multicolumn{11}{|c|}{ Cost coefficients } \\
\hline & & $\begin{array}{l}\mathrm{A} \\
\left(\$ / \mathrm{MWh}^{2}\right)\end{array}$ & $\begin{array}{l}\mathrm{B} \\
(\$ / \mathrm{MWh})\end{array}$ & $\begin{array}{l}\mathrm{C} \\
(\$)\end{array}$ & $\begin{array}{l}\text { Pmax } \\
\text { (MW) }\end{array}$ & $\begin{array}{l}\text { Pmin } \\
\text { (MW) }\end{array}$ & $\begin{array}{l}\text { Min up } \\
\text { time (h) }\end{array}$ & $\begin{array}{l}\text { Min down } \\
\text { time }(\mathrm{h})\end{array}$ & $\begin{array}{l}\text { Ramp up } \\
\text { (MW) }\end{array}$ & $\begin{array}{l}\text { Ramp down } \\
\text { (MW) }\end{array}$ & $\begin{array}{c}\text { Startup } \\
\text { ramp } \\
\text { (MW) }\end{array}$ & $\begin{array}{c}\text { Shutdown } \\
\text { ramp } \\
\text { (MW) }\end{array}$ \\
\hline G1 & 1 & 0.0200 & 15.00 & 0 & 80 & 15 & 2 & 2 & 25 & 25 & 70 & 60 \\
\hline $\mathrm{G} 2$ & 2 & 0.0175 & 14.75 & 0 & 80 & 15 & 2 & 2 & 25 & 25 & 70 & 60 \\
\hline G3 & 13 & 0.0250 & 16.00 & 0 & 50 & 10 & 3 & 3 & 15 & 15 & 70 & 60 \\
\hline $\mathrm{G} 4$ & 22 & 0.0625 & 14.00 & 0 & 50 & 10 & 4 & 4 & 15 & 15 & 70 & 60 \\
\hline G5 & 23 & 0.0250 & 16.00 & 0 & 30 & 5 & 3 & 3 & 10 & 10 & 70 & 60 \\
\hline G6 & 27 & 0.0083 & 15.25 & 0 & 55 & 10 & 4 & 4 & 15 & 15 & 70 & 60 \\
\hline
\end{tabular}

\section{REFERENCES}

Bansal, R.C., 2005. Optimization methods for electric power systems: An overview. Int. J. Emerging Electric Power Syst., 2: 1021-1021.

Bhavani, S.V.D. and K.R. Kumar, 2014. Novel genetic algorithm based solutions for optimal power flow under contingency conditions. Intl. J. Eng. Res. Appl., 4: 20-30.

Bukhsh, W.A., A. Grothey, K.I.M. McKinnon and P.A. Trodden, 2013. Local solutions of the optimal power flow problem. IEEE. Trans. Power Syst., 28: 4780-4788.

Ding, T., R. Bo, F. Li and H. Sun, 2015. Optimal power flow with the consideration of flexible transmission line impedance. IEEE. Trans. Power Syst., 31: 1655-1656.

Hoolimath, P.K.G., M. Kiran and G.R.M. Reddy, 2012. Optimized termite: A bio-inspired routing algorithm for MANET's. Proceedings of the International Conference on Signal Processing and Communications (SPCOM), July 22-25, 2012, IEEE, Bangalore, India, ISBN:978-1-4673-2013-9, pp: 1-5.
Mohamed, K.H., K.S.R. Rao and K.N.B.M. Hasan, 2009. Optimal power flow and interline powers flow controllers using particle swarm optimization technique. Proceedings of the IEEE International Conference on TENCON 2009-2009 Region 10, January 23-26, 2009, IEEE, Singapore, ISBN: 978-1-4244-4546-2, pp: $1-6$.

Wang, H., C.E. Murillo-Sanchez, R.D. Zimmerman and R.J. Thomas, 2007. On computational issues of market-based optimal power flow. IEEE. Trans. Power Syst., 22: 1185-1193.

Weedy, B.M., B.J. Cory, N. Jenkins, J.B. Ekanayake and G. Strbac, 2012. Electric Power Systems. 5th Edn., John Wiley \& Sons, Hoboken, New Jersey, USA., ISBN: 9781118361085 , Pages: 512.

Zhang, H. and P. Li, 2010. Probabilistic analysis for optimal power flow under uncertainty. IET. Gener. Transm. Distrib., 4: 553-561. 